\title{
Fabrication of polylactic acid/paclitaxel nano fibers by electrospinning for cancer therapeutics
}

\author{
H. Y. Chi ${ }^{1,3}$, Vincent Chan ${ }^{2 *} \mathbb{0}$, Chuan Li ${ }^{3^{*}}$, J. H. Hsieh ${ }^{4}$, P. H. Lin ${ }^{3}$, Ya-Hui Tsai ${ }^{5}$ and Yun Chen ${ }^{5}$
}

\begin{abstract}
Polylactic acid (PLA) is a thermoplastic and biodegradable polyester, largely derived from renewable resources such as corn starch, cassava starch and sugarcane. However, PLA is only soluble in a narrow range of solvents such as tetrahydrofuran, dioxane, chlorinated solvents and heated benzene. The limited choices of solvent for PLA dissolution have imposed significant challenges in the development of specifically engineered PLA nanofibers with electrospinning techniques. Generally, the electrospun polymeric materials have been rendered with unique properties such as high porosity and complex geometry while maintaining its biodegradability and biocompatibility for emerging biomedical applications. In this study, a new anticancer drug delivery system composed of PLA nanofibers with encapsulated paclitaxel was developed by the electrospinning of the respective nanofibers on top of a spin-coated thin film with the same chemical compositions. Our unique approach is meant for promoting strong bonding between PLAbased nanofibers and their respective films in order to improve the prolonged release properties and composite film stability within a fluctuative physiochemical environment during cell culture. PLA/paclitaxel nanofiber supported on respective polymeric films were probed by scanning electronic microscope, Fourier transform infrared spectrometer and water contact measurement for determining their surface morphologies, fibers' diameters, molecular vibrational modes, and wettability, respectively. Moreover, PLA/paclitaxel nanofibers supported on respective spin-coated films at different loadings of paclitaxel were evaluated for their abilities in killing human colorectal carcinoma cells (HCT116). More importantly, MTT assays showed that regardless of the concentrations of paclitaxel, the growth of HCT-116 was effectively inhibited by the prolonged release of paclitaxel from PLA/paclitaxel nanofibers. An effective prolonged delivery system of paclitaxel based on PLA nanofiber-based film has demonstrated exciting potentials for emerging applications as implantable drug delivery patch in post-surgical cancer eradication.
\end{abstract}

Keywords: Polylactic acid, Paclitaxel, Electrospinning, Spin coating, Human colorectal carcinoma

\section{Introduction}

Polylactic acid (PLA) is a condensation thermoplastic elastomers with demonstrated low cytotoxicity and good biodegradability and has similar properties compared to those of polypropylene, polyethylene, or polystyrene. Moreover, PLA is an aliphatic (non-aromatic) polymer

\footnotetext{
*Correspondence: vincent.chan@ku.ac.ae; cli10@yahoo.com

${ }^{2}$ Department of Biomedical Engineering, Khalifa University, PO

Box 127788, Abu Dhabi, United Arab Emirates

${ }^{3}$ Department of Biomedical Engineering, National Yang Ming University,

Taipei 11221, Taiwan

Full list of author information is available at the end of the article
}

with a glass transition temperature of around $60{ }^{\circ} \mathrm{C}$ and melting points between 130 and $180{ }^{\circ} \mathrm{C}$. Interestingly, the usage of PLA is highly sustainable because its monomers can be obtained from various types of agricultural by-products such as sugarcane, corn starch or cassava roots and can be later on reused as carbon sources for plants after degradation and decomposition. As a result, PLA is relatively cost-effective for large scale production through direct condensation of lactic acid monomers $\left(\sim 100-160{ }^{\circ} \mathrm{C}\right)$ or ring-opening polymerization of lactide on metal catalysts. Most importantly, raw material of PLA can be fabricated into different sizes and shape by various common fabrication techniques such as plastic

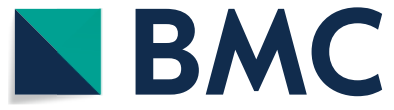

(c) The Author(s) 2020. This article is licensed under a Creative Commons Attribution 4.0 International License, which permits use, sharing, adaptation, distribution and reproduction in any medium or format, as long as you give appropriate credit to the original author(s) and the source, provide a link to the Creative Commons licence, and indicate if changes were made. The images or other third party material in this article are included in the article's Creative Commons licence, unless indicated otherwise in a credit line to the material. If material is not included in the article's Creative Commons licence and your intended use is not permitted by statutory regulation or exceeds the permitted use, you will need to obtain permission directly from the copyright holder. To view a copy of this licence, visit http://creativeco mmons.org/licenses/by/4.0/. The Creative Commons Public Domain Dedication waiver (http://creativecommons.org/publicdomain/ zero/1.0/) applies to the data made available in this article, unless otherwise stated in a credit line to the data. 
extrusion, casting, injection molding and spin coating or even 3D printing [1-6]. Thus PLA is an attractive platform for various emerging applications in drug delivery, gene therapy and regenerative medicine.

Paclitaxel (PLX) is an organic compound extracted from the bark of a Pacific yew tree known as Taxus brevifolia. It belongs to the taxane family which serves as antineoplastic drugs by inhibiting the disassembly of microtubules in cancerous cells through the binding to intracellular GDP-bound tubulins. The binding as mentioned above directly destabilizes the microtubules by stopping the de-polymerization of $\beta$-tubulin dimers from microtubules, leading to the disruptions of cell division during mitotic and interphase cellular functions [7-10]. PLX is a prescribed-only, chemotherapeutic medication to treat a few types of cancer. In clinical setting, PLX currently plays a central role as a chemotherapy medication in the treatment of cervical cancer, breast cancer, ovarian cancer, lung cancer, pancreatic cancer, and Kaposi sarcoma. In general, PLX in its original form or newer albumin-bound formulation is usually administrated to patients by intravenous (IV) injection or infusion. The high efficacy of PLX in anticancer therapy has been proven by the absence of elevated liver enzymes without leading to acute liver injury [11-13]. On the other hand, the current formulation of PLX includes Kolliphor which often causes allergic reactions to patients.

On top of the ideal properties for PLA for biomedical applications, random, PLA nanofiber offers complex 3-dimensional microscopic and nanoscale structures for the encapsulation of drugs and hosting of regenerative cells [6]. Moreover, the recent success in using albumin to bound PLX into sub-micron particle, emerging drug delivery system like PLA nanofiber should offer an promising alternative for the prolonged delivery of PLX. In order to evaluate the performance of PLA nanofiber for prolonged PLX delivery, PLA/PLX nanofibers in the form of membrane were fabricated from PLA/PLX mixed solution by electrospinning on top of PLA/PLX thin film with the same composition by spin coating. PLA/PLX thin film spun coated on glass should not lead to significant interference with drug delivery studies involving the supported PLA/ PLX nanofibers lying above. Since both thin film and nanofibers as mentioned above had the same chemical composition, strong bonding between the two forms of PLA/PLX should be naturally enforced upon the nanofiber deposition on thin film. To the best of our knowledge, the fabrication of drug delivery patch of PLA/PLX nanofibers immobilized on the same polymer thin film against the change of PLX concentrations aiming for anti-cancer drug delivery has not been reported previously. In this study, the structure, morphology, and compositions of the PLA/PLX nanofibers were thoroughly characterized. In detail, scanning electron microscope (SEM) and Fourier transform infrared spectrometer (FTIR) was applied to probe the nanofiber topology and vibrational modes of chemical bonds, respectively. For exploring the potential of PLA/ PLX nanofiber membrane in sustained drug delivery for post-surgical site of tumor removal, the tumor killing efficacy of PLA/PLX nanofiber membrane were measured with in vitro MTT assays (for cell proliferation and cell cycle) through their bio-toxicity against model cell line of neuroblastoma, which is the most common cancer among young children.

\section{Methods}

The experimental setup for the study PLA/PTX nanofiber and thin films is laid out in Fig. 1. It needs to be noted that either nanofiber or thin films used herein is prepared from a mixture of PLA (40 wt.\%) and paclitaxel. In general, nanofiber membrane are fabricated by electrospinning technique while thin film is formed by spin coating on a glass substrate. For material characterizations and biological studies, we place various samples of PLA/ PTX nanofiber membrane on top of thin film of same

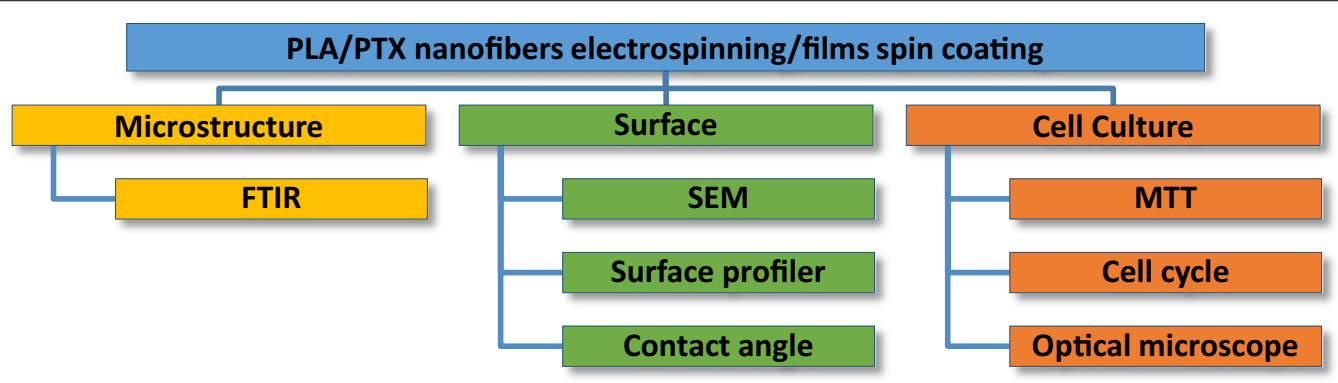

Fig. 1 Experiment study for the electrospun paclitaxel mixed PLA nanofibers on top of a thin film of same compositions 
composition which was spin-coated on a glass substrate for convenient measurements in various instruments.

\section{Substrate and materials}

Glass coverslips (Corning 1737) were cut into a dimension of $10 \mathrm{~mm} \times 10 \mathrm{~mm}$ by tungsten cutter and then ultrasonically cleaned in $\mathrm{KOH}(85 \%)$, followed by acetone (99.9\%), DI water, and finally by alcohol (90\%). Each cleaning step took around $10 \mathrm{~min}$. After thorough cleaning, the glass substrates were blown to dry by nitrogen gas.

Poly(L-lactide) (, $\left[\mathrm{CH}_{\mathrm{CH}_{3}}^{\mathrm{O}} \mathrm{O}\right]_{\mathrm{n}}$, Synthesis $\left.\mathrm{C}_{3} \mathrm{H}_{4} \mathrm{O}_{2}\right]_{\mathrm{n}}, \mathrm{CAS}$ 26161-42-2, FL-94829, Sigma-Aldrich, St. Louis, MO USA) made from lactide ( to light yellow powder was dissolved in trifluoroacetic acid (TFA, 99\%, $\mathrm{CF}_{3} \mathrm{CO}_{2} \mathrm{H}$, $\mathrm{HO}_{\mathrm{CF}_{3}}$, CAS 76-05-1, Alfa Aesar, Ward Hill, MA USA) and then continuously stirred for $24 \mathrm{~h}$ at room temperature before used for electrospinning. The concentration of PLA solution is listed in Table 1. Paclitaxel (CAS: 33069-62-4, $\mathrm{C}_{47} \mathrm{H}_{51} \mathrm{NO}_{14}$ ) purchased from Sigma-Aldrich Inc. (UNI-ONWARD Corp. New Taipei City, Taiwan) in a powder form was dissolved in dimethyl sulfoxide (DMSO, CAS: 67-68-5, $\mathrm{C}_{2} \mathrm{H}_{6} \mathrm{OS}$, Sigma-Aldrich, UNI-ONWARD Corp. New Taipei City, Taiwan). To obtain the best quality in the electrospun nanofibers, paclitaxel/DMSO solution $(2.5 \mathrm{mg} / 100 \mu \mathrm{l}(50 \%)$ or $5 \mathrm{mg} / 100 \mu \mathrm{l}(100 \%))$ was mixed with PLA (40 wt.\%) solution by using the volumetric ratio of PLA/paclitaxel $=3 \mathrm{ml}: 200 \mu \mathrm{l}$ to form the finalized polymer solution for either spin coating or electrospinning.

\section{Spin coating}

First of all, glass substrates were treated by reactive-ion etching (RIE, 50w, Ar and $\mathrm{O}_{2}$ flow rates of $30 \mathrm{sccm}$ ) for $30 \mathrm{~min}$ in order to increase the surface hydrophilicity. Then PLA/PTX thin film with various compositions was produced by spin coating (SWIENCO SP-02, Power Assist Instrument Scientific Corp. Taoyuan, Taiwan) on glass substrate in a solution mixture of PLA and PTX. The optimized spinning speed of $3000 \mathrm{rpm}$ was set to from different types of PLA/paclitaxel thin films. All coating processes were completed within $4 \mathrm{~min}$ in order to allow the solution to cover across the entire glass substrate. After coating, we let the sample to dry for around $30 \mathrm{~min}$ in atmosphere environment before electrospinning of the polymeric nanofibers on top of the PLA/paclitaxel thin films.

\section{Electrospinning of nanofiber membrane}

The electrospinning of PLA/PTX was carried with commercially available electrospinning system (FES-COE, Falco, Taiwan) which consists of a syringe pump, a power supply and a two-dimensional motorized platform (collector) for the glass substrate. In brief, the solution mixture of PLA and PTX was first drawn into a glass syringe before the eventual deposition onto a substrate. The operational parameters of the electrospinning process are listed in Table 1. It must be noted that the distance between the syringe's needle tip and substrate is optimized by trial and

Table 1 Parameters for deposition of PLA/paclitaxel mixed layer film by spin coating and nanofibers by electrospinning

\begin{tabular}{|c|c|}
\hline \multicolumn{2}{|c|}{ Process parameters for PLA/paclitaxel films by spin coating } \\
\hline Speed (rpm) & 3000 \\
\hline Operational temperature $\left({ }^{\circ} \mathrm{C}\right)$ & Room temperature \\
\hline Deposition time (min) & 4 \\
\hline PLA concentration in TFA (wt.\%) & 40 \\
\hline Paclitaxel concentration in DMSO & $2.5 \mathrm{mg} / 100 \mu \mathrm{l}(50 \%), 5 \mathrm{mg} / 100 \mu \mathrm{l}(100 \%)$ \\
\hline \multicolumn{2}{|c|}{ Process parameters for PLA/paclitaxel nanofibers by electrospinning } \\
\hline Voltage (kV) & 17 \\
\hline Flow rate $(\mu \mathrm{l} / \mathrm{min})$ & $1 \times 10^{-2}$ \\
\hline Syringe outer/inner diameter (mm) & $5.0 \times 10^{-1} / 2.6 \times 10^{-1}$ \\
\hline Operational temperature $\left({ }^{\circ} \mathrm{C}\right)$ & Room temperature \\
\hline Working distance $(\mathrm{cm})$ & 14 or 15 \\
\hline Deposition time (s) & $>60$ \\
\hline PLA concentration in TFA (wt.\%) & 40 \\
\hline Paclitaxel concentration in DMSO & $2.5 \mathrm{mg} / 1 \mathrm{ml}(50 \%), 5 \mathrm{mg} / 1 \mathrm{ml}(100 \%)$ \\
\hline Volumetric mixing ratio (PLA: Paclitaxel) & $3 \mathrm{ml}: 200 \mu \mathrm{l}$ \\
\hline
\end{tabular}


errors for depositing PLA/PTX nanofiber membrane with uniform thickness. The dimension (diameter) of nanofibers is controlled by both applied voltage and flow rate. In general, the higher the applied voltage or flow rates, the thinner the fibers were produced. However, exceedingly high voltage often induces arching between the glass substrate and needle, which leads to the breakup of a streaming jet into droplets. Physical parameters in Table 1 were chosen after many rounds of process optimization in order to assure the highly reproducible properties of PLA/paclitaxel nanofibers.

\section{Characterization}

\section{Surface morphology of layer film and nanofibers}

The diameters of electrospun PLA/paclitaxel fibers were measured from images by scanning electron microscope (SEM, S-3400 N, Hitachi, Japan) with Image J software. For SEM measurement, the voltage of the accelerated electron beam is set at $15 \mathrm{kV}$ and the magnification is chosen to be $2000 \times$ for the best resolution. The average and variances of the nanofiber diameters is averaged from 15 to 20 fibers randomly selected across the entire region of any SEM image.

\section{Molecular structure}

To determine the vibrational modes of molecular bonding in the deposited PLA/paclitaxel layer films and nanofibers, Fourier transformed infrared spectrometer, FTIR (Perkin-Elmer Pentagon 1005, USA) equipped with $\mathrm{He}-\mathrm{Ne}$ laser as excitation source at $632.8 \mathrm{~nm}(25 \mathrm{~mW}))$ was used to detect the infrared absorption of the samples in the range of $450-4000 \mathrm{~cm}^{-1}$ with a resolution of $1 \mathrm{~cm}^{-1}$ in reflection mode. The FTIR spectrum of a plain glass substrate was first probed with FTIR and used as a control for comparing with those of other samples. Moreover, the IR detector is set at the backside of each sample. The spectrum was numerically analyzed with Fityk 0.9.8 software using Gaussian fitting to identify all peaks against the vibrational modes of various types of chemical bonds. Major FTIR absorption peaks of both PLA and paclitaxel from previous studies are listed in Table 2 [4, 6, 14-29].

\section{Contact angle measurement}

The contact angles of deposited films were measured from the image of water droplets $(1 \mathrm{ml})$ on the surface of each sample as taken by a CCD camera (Watec, WAT902B, Watec Corp, Japan). Images were further analyzed
Table 2 Selected FTIR absorption peaks for PLA [14-24] and paclitaxel [14-29]

\begin{tabular}{|c|c|}
\hline Wavenumber $\left(\mathrm{cm}^{-1}\right)$ & Mode \\
\hline \multicolumn{2}{|l|}{ PLA } \\
\hline 616 & COO-bend \\
\hline 806 & COO-(out-of-plane) \\
\hline 973 & C-N stretching \\
\hline 1022 & - $\mathrm{CH}_{2}$ (out-of-plane) \\
\hline 1090 & $\mathrm{C}-\mathrm{O}$ stretching \\
\hline 1183 & $-\mathrm{C}-\mathrm{O}-\mathrm{C}-$ \\
\hline 1224 & $-\mathrm{C}-\mathrm{O}-\mathrm{H}-$ \\
\hline 1305 & C-H (out-of-plane) \\
\hline 1339 & $\mathrm{C}-\mathrm{H}$ bending \\
\hline 1434 & COO-symmetric stretching \\
\hline 1470 & $-\mathrm{CH}_{2}$ bending \\
\hline 1601 & COO-asymmetric stretching \\
\hline 1746 & $\mathrm{C}=\mathrm{O}$ stretching \\
\hline 2905 & $\mathrm{C}-\mathrm{H}$ stretching \\
\hline 2956 & $-\mathrm{CH}_{2}$ symmetric stretching \\
\hline 3004 & $-\mathrm{CH}_{2}$ asymmetric stretching \\
\hline 3568 & $\mathrm{OH}(\mathrm{COOH})$ \\
\hline 3572 & $\mathrm{OH}(\mathrm{COOH})$ \\
\hline \multicolumn{2}{|l|}{ Paclitaxel } \\
\hline 689 & $\mathrm{C}-\mathrm{H}$ out-of-plane/ $\mathrm{C}-\mathrm{C}=\mathrm{O}$ deformation \\
\hline $803-941$ & C-H in-plane deformation \\
\hline $941-803$ & $\mathrm{C}-\mathrm{H}$ in-plane deformation \\
\hline 1049-1090 & $\mathrm{C}-\mathrm{O}$ stretching \\
\hline $1112-1117$ & $\mathrm{O}-\mathrm{H}$ in-plane bending in $(\mathrm{COOH})$ \\
\hline 1274 & C-N stretching \\
\hline $1330-1380$ & $\mathrm{CH}_{3}$ deformation \\
\hline 1369 & $\mathrm{CH} / \mathrm{NH}$ bend \\
\hline 1444 & $\mathrm{C}=\mathrm{C}$ ring stretching \\
\hline $1579-1652$ & C-C stretching \\
\hline 1640 & $\mathrm{~N}-\mathrm{H}$ bending \\
\hline 1733 & ( $\mathrm{C}=\mathrm{O}$ stretching) of amide group \\
\hline 1775 & $\mathrm{C}=\mathrm{O}$ \\
\hline 1777 & $\mathrm{C}=\mathrm{O}$ \\
\hline $2541-2973$ & $\mathrm{CH} 3 / \mathrm{C}-\mathrm{H}$ stretching \\
\hline 2860 & $\mathrm{CH}$ \\
\hline 2909 & $\mathrm{CH}$ stretch \\
\hline 3066 & -CH sp ${ }^{3}$ stretching \\
\hline 3339 & $\mathrm{~N}-\mathrm{H} / \mathrm{O}-\mathrm{H}$ stretching \\
\hline 3568 & $\mathrm{OH}(\mathrm{COOH})$ \\
\hline 3572 & $\mathrm{OH}(\mathrm{COOH})$ \\
\hline
\end{tabular}

by Image J (ver. 1.52k released on 29 January 2019, National Institute of Health US) to obtain the contact angle. 


\section{Cancer cell culture Cell preparation}

Human colorectal carcinoma cells (HCT-116) were purchased from Bioresource Collection and Research Center (Hsinchu, Taiwan) for our study. These cells were stored in Ependroff tubes and kept in $-20{ }^{\circ} \mathrm{C}$ freezer until use. Before each experiment, a batch of cells was first incubated and shaken in water bath at $37{ }^{\circ} \mathrm{C}$ for about $30 \mathrm{~min}$. After temperature equilibration, HCT-116 containing suspension is pipetted into the fresh culture medium (Dulbecco's Modified Eagle Medium/High Glucose powder, Gibco ${ }^{\circledR}$, Thermo Fisher Scientific, USA) inside a petri dish of $10 \mathrm{~cm}$ in diameter. Using the existing established protocol, we cultured HCT-116 in an temperature-controlled incubator (ShelLab, 2424IR, USA) at $37{ }^{\circ} \mathrm{C}$ with a supply of $5 \%$ $\mathrm{CO}_{2}$ and $95 \%$ relative humidity. The cells were typically cultured for 2 to 3 days before they were trypsinized and pipetted into clean Ependroff tubes. The entire suspension in Ependroff tubes was then centrifuged for $3 \mathrm{~min}$ at $1300 \mathrm{rpm}$. After centrifugation, the supernatant was discarded and cells containing sediment were resuspended in culture medium before loading into a 24-well plate for subsequent tests. The concentration of seeding cells was set at around $10^{5}$ cells $/ 500 \mu \mathrm{l}$ in order to avoid over-crowding or under-growing of cells in the subsequent culture. For cell culture study, all PLA/paclitaxel nanofiber samples were sterilized by UV light for at least $15 \mathrm{~min}$ and then placed in a 24-well dish for all biological tests.

\section{Cell cycle test}

First, PLA/paclitaxel samples were loaded in a 6-well plate and submerged in fresh culture medium before placing inside the $\mathrm{CO}_{2}$ incubator. After $2 \mathrm{~h}$ incubation, HCT-116 cells at a cell density of around $10^{5}$ cells/500 $\mu \mathrm{l}$ were loaded into the wells of 12-well plate. Followed by an additional round of incubation for $24 \mathrm{~h}$, the 12-well plates were taken out from incubator and the cell containing suspension were subjected to centrifugation in order to remove supernatant. Next, the cell concentration was reduced from $5 \times 10^{5}$ to $1 \times 10^{6}$ cells $/ 500 \mu \mathrm{l}$ in every sample. The dilution process involves the addition of Solution 10 lysis buffer (acidic aqueous solution, ChemoMetec) mixed with DAPZ (volumetric ratio 1000:1) and Solution 11 stabilization buffer (basic aqueous solution, ChemoMetec). After the dilution, the stained cells were transferred to A8 slides (NC-Slide A8, ChemoMetec A/S Danmark), which were later analyzed by Chemometec NucleoCounter ${ }^{\circledR}$ (NC-3000, ChemoMetec A/S Danmark) for cell counting and cell cycles assay.

\section{Cell viability}

MTT is a yellowish and water-soluble tetrazolium salt (3-[4,5-dimethylthiazol-2-yl]-2,5-diphenyltetrazolium- bromide) and is used for measuring viability of cells. In the presence of nicotinamide adenine dinucleotide (generated by active metabolism in cells), the tetrazolium dye contained in MTT is oxidized through the reduction of $\mathrm{NADH}$ to $\mathrm{NAD}^{+}$, leading to the formation of insoluble formazan with purple color. The insoluble formazan deposited on the cell surface was dissolved with isopropanol or other organic solvents. The dissolved solution has representative optical absorbance peaks at 562 and $650 \mathrm{~nm}$ identifiable by a spectrophotometer (Epoch 2, Microplate Spectrophotometer, BioTek Instruments Inc. USA), whose intensities are proportional to the concentration of formazan. As MTT is found in all living cells, its concentration can be used as a reliable marker for quantifying the number of viable cells. The average intensity of both absorption peaks is usually expressed as optical density (OD) which is defined as

$$
\mathrm{OD}=\log _{10}\left(\frac{\text { incident light intensity }}{\text { transmitted light intensity }}\right)
$$

To estimate the amount of released paclitaxel from PLA/paclitaxel mixed nanofiber, we first established a benchmark chart for the optical density from MTT assay on the culture of HCT-116. The culture follows the procedure mentioned earlier. This chart, as shown in Fig. 2, represents the variation of optical density ratios against different concentrations of paclitaxel in the culture media. A regression curve of a rational function with fractional power is numerically determined using CurveExpert Basic 2.0 (Hyams Development, Tennessee, USA). This function provides a good fit to the data with a standard error of 0.0719 and the correlation coefficient 0.9831 . The regression provides us with a numerical estimation on the concentration of paclitaxel in the culture medium.

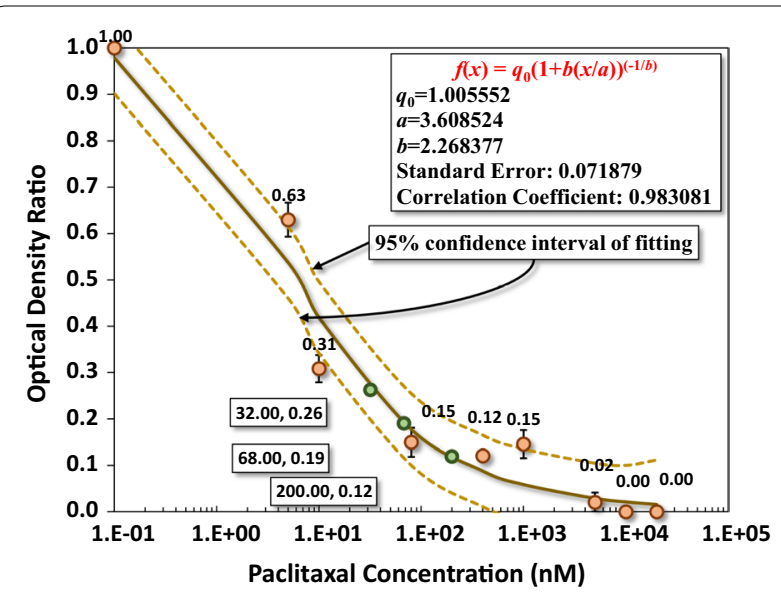

Fig. 2 The benchmark test for the optical density ratio from MTT assay on the culture of HCT-116 as a function of paclitaxel concentration in the culture medium 
For example, the optical density ratio is around 0.12 for the concentration of paclitaxel at $200 \mathrm{nM}$. This concentration marks the upper bond of a low concentration of paclitaxel for anticancer effects as reported in the literature [38-42]. In Fig. 8, the concentration of paclitaxel released from PLA/paclitaxel nanofibers can be calculated to be 32 and $68 \mathrm{nM}$ for the optical density ratio of 0.26 and 0.19 , respectively.

\section{Results}

\section{Morphology of electrospun PLA}

SEM images of plain PLA nanofiber and other PLA nanofiber membranes with different concentrations of encapsulated paclitaxel were presented in Fig. 3. The result indicated that nanofibers of pure PLA and PLA incorporated with paclitaxel displayed uniform fiber size and contour length across the entire region of deposition area while the formation of spindles was negligible after the electrospinning process. Moreover, it was shown that plain PLA nanofibers possessed smooth surface morphology without the formation of detectable pores. To quantify the nanofibers' dimension, the diameter of at least 15 nanofibers were randomly selected from each SEM image of membrane and were measured with image analysis software. The average diameters of nanofibers for three different membrane samples were summarized in Fig. 4. The result indicated that all samples displayed nanofibers with averaged diameters ranging from 0.36 to $0.43 \mu \mathrm{m}$.

\section{Fourier-transform infrared spectroscopy (FTIR)}

FTIR reveals the molecular features on polymeric thinfilm through the determination of the unique vibrational modes of various chemical groups. FTIR spectra in the range of $500-3500 \mathrm{~cm}^{-1}$ for spin-coated PLA thin films mixed with different concentrations of paclitaxel (PLA+PTX50\% and PLA+PTX100\%) were shown in Fig. 5, with all absorption peaks fitted by Gaussian fitting in each sample's spectrum. The FTIR spectra of plain PLA and pure paclitaxel were shown alongside as controls. In general, major FTIR peaks of plain PLA determined by Gaussian fitting included the following vibrational groups: $\mathrm{C}-\mathrm{O}$ stretch at $\sim 1087 \mathrm{~cm}^{-1}, \mathrm{C}-\mathrm{O}-\mathrm{C}$ at $\sim 1183 \mathrm{~cm}^{-1}, \mathrm{O}=\mathrm{C}-\mathrm{O}$ in ester groups at $\sim 1755 \mathrm{~cm}^{-1}$, $\mathrm{O}=\mathrm{C}-\mathrm{O}$ stretch in ester groups at $\sim 1130 \mathrm{~cm}^{-1}$ and $\mathrm{CH}_{3}$ at $1458 \mathrm{~cm}^{-1}$. The result as mentioned above corresponded well with all the basic chemical groups found along the backbone of PLA. For PTX, major vibrational modes included $\mathrm{C}-\mathrm{H}$ out-of-plane or $\mathrm{C}-\mathrm{C}=\mathrm{O}$ deformation at $689 \mathrm{~cm}^{-1}, \mathrm{C}-\mathrm{H}$ in-plane deformation at $803 \sim 941 \mathrm{~cm}^{-1}, \mathrm{C}-\mathrm{O}$ stretching at $1049 \sim 1090 \mathrm{~cm}^{-1}$,
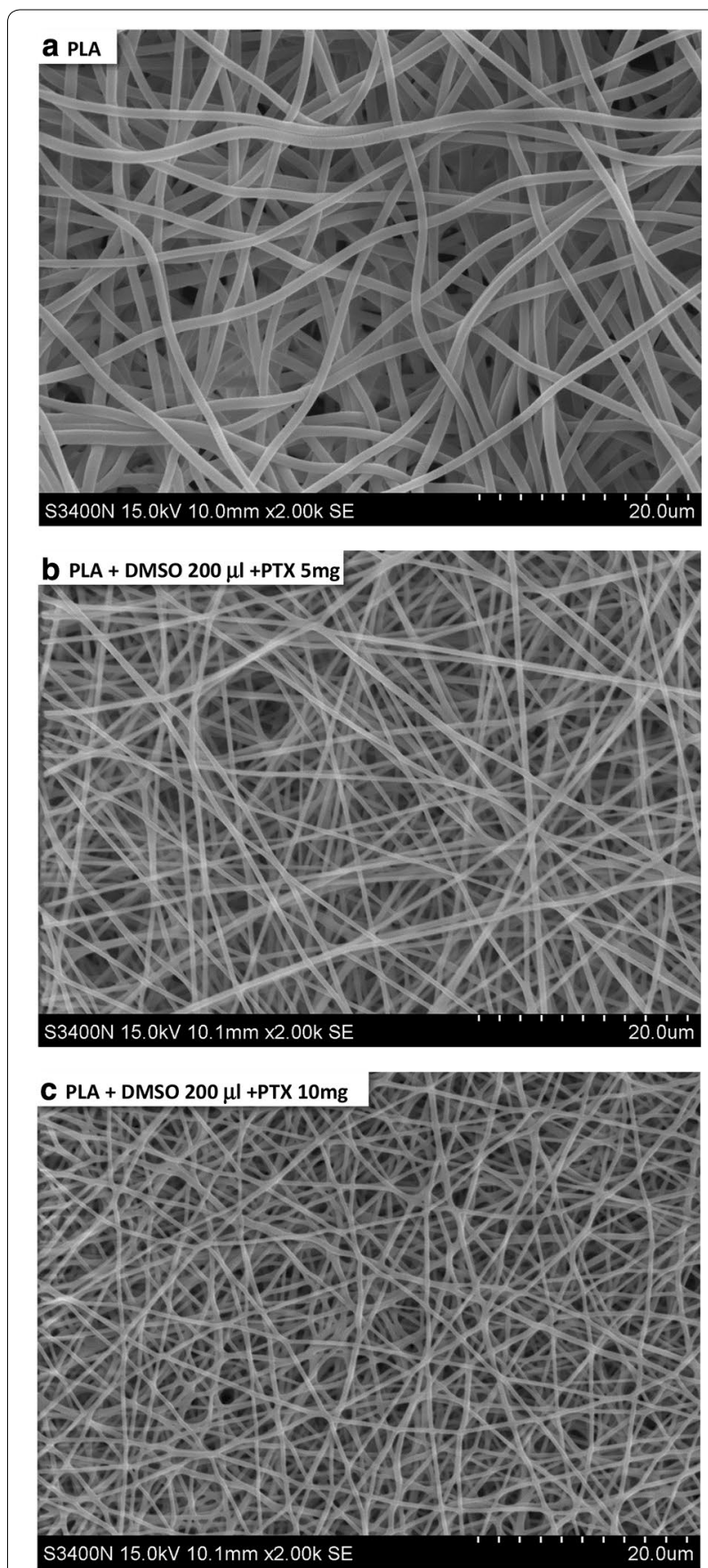

Fig. 3 Morphology of electrospun PLA/paclitaxel mixed nanofibers

$\mathrm{C}-\mathrm{N}$ stretching at $1274 \mathrm{~cm}^{-1}, \mathrm{CH}_{3}$ deformation at $1330 \sim 1380 \mathrm{~cm}^{-1}, \mathrm{C}=\mathrm{C}$ ring stretching at $1444 \mathrm{~cm}^{-1}$, $\mathrm{C}-\mathrm{C}$ stretching at $1579 \sim 1652 \mathrm{~cm}^{-1}, \mathrm{~N}-\mathrm{H}$ bending at $1640 \mathrm{~cm}^{-1}, \mathrm{C}=\mathrm{O}$ stretching at $1720 \sim 1727 \mathrm{~cm}^{-1},(\mathrm{C}=\mathrm{O}$ stretching) of amide group at $1733 \mathrm{~cm}^{-1}, \mathrm{CH} / \mathrm{C}-\mathrm{H}$ stretching at $2541 \sim 2973 \mathrm{~cm}^{-1},-\mathrm{CH} \mathrm{sp}{ }^{3}$ stretching at $3066 \mathrm{~cm}^{-1}, \mathrm{~N}-\mathrm{H} / \mathrm{O}-\mathrm{H}$ stretching at $3339 \mathrm{~cm}^{-1}$, agreed 


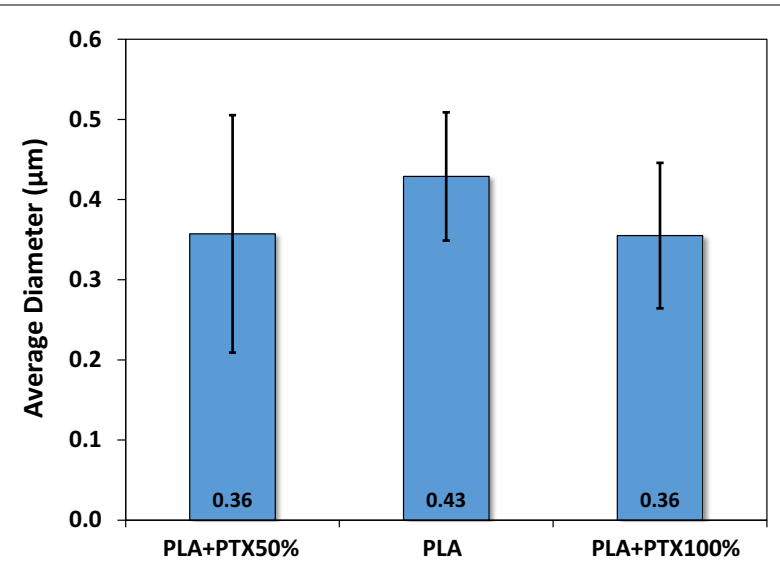

Fig. 4 Averaged diameters for electrospun PLA/paclitaxel mixed nanofibers. At least 30 fibers are randomly selected from each image of SEM

with those peaks of pure paclitaxel as reported in the literature [4, 6, 14-29]. Those main and minor vibrational modes of plain PLA and pure paclitaxel were summarized in Table 2.

\section{Contact angle measurement}

The averaged contact angles of PLA, PLA+PTX50\% and PLA+PTX100\% nanofiber membrane, supported on respective spun coated thin film were shown in Fig. 6. Regardless of the composition, the water contact angles of all samples were larger than $90^{\circ}$, implying high hydrophobicity displayed on these nanofibers. However, the incorporation of PTX into PLA matirx made the nanofiber coated substrate less hydrophobic as show by averaged water contact angles of $119.7^{\circ}$ and $124.5^{\circ}$ in PLA+PTX50\% and PLA+PTX100\%, respectively, compared to the higher average of of $139.8^{\circ}$ in pure PLA.

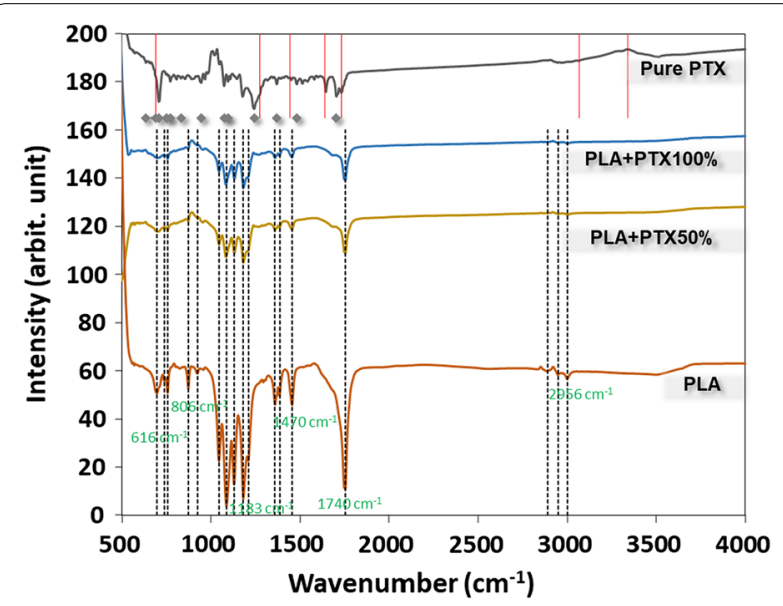

Fig. 5 FTIR spectra for electrospun PLA layer films with different concentrations of paclitaxel

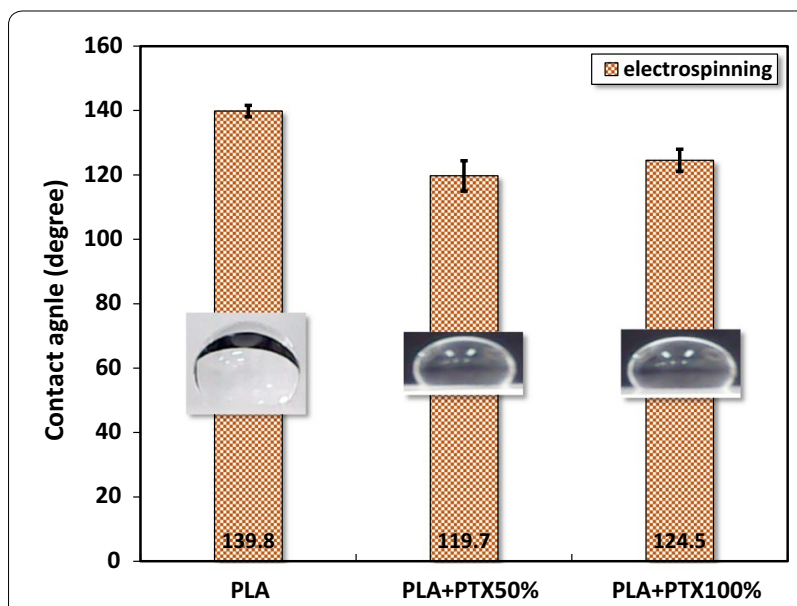

Fig. 6 Contact angle for PLA/paclitaxel mixed nanofibers. All photos are images of water drops on nanofibers

\section{Cell culture}

\section{Biocompatibility of pure PLA nanofibers and films}

To ensure that PLA or PLA/PTX nanofiber membrane impose negligible cytotoxicity, each sample was immersed in plain culture medium for $72 \mathrm{~h}$ which was subsequently extracted for culturing HCT-116 cells in vitro. For the ease of direct comparison between the three types of nanofiber membranes, MTT data in terms of optical density ratio $\left(\frac{\mathrm{OD}_{\text {specific sample }}}{\mathrm{OD}_{\text {control }}}\right)$ instead of individual MTT data. Figure 7 showed the optical density ratio of HCT-116 cells determined from MTT assay at $48 \mathrm{~h}$ after culturing in the three types of extracted liquid medium. The result indicated that the optical density ratio of HCT-116 cells incubated with extracted culture medium from glass, PLA thin film and PLA nanofiber membrane stays at around one.

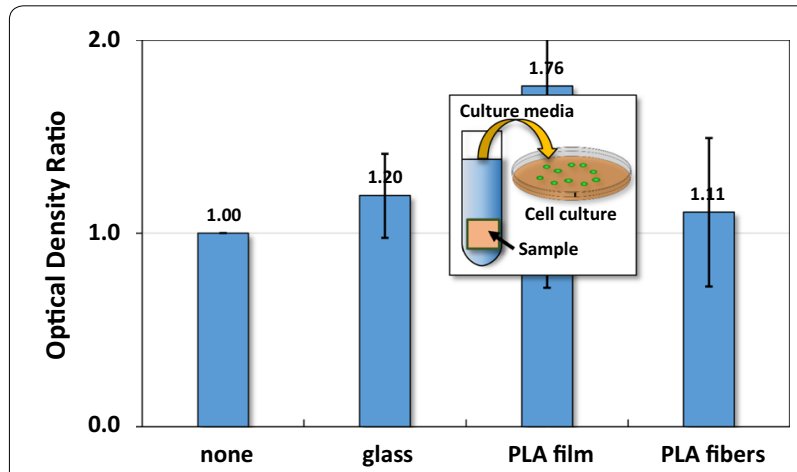

Fig. 7 MTT assay for HCT-116 cultured in media from pure PLA films and nanofibers. The optical density is $\log _{10}\left(\frac{\text { incident light intensity }}{\text { transmitted light intensity }}\right)$ and the optical density ratio is $\frac{O D_{\text {specific group }}}{O D_{\text {control }}}$ 


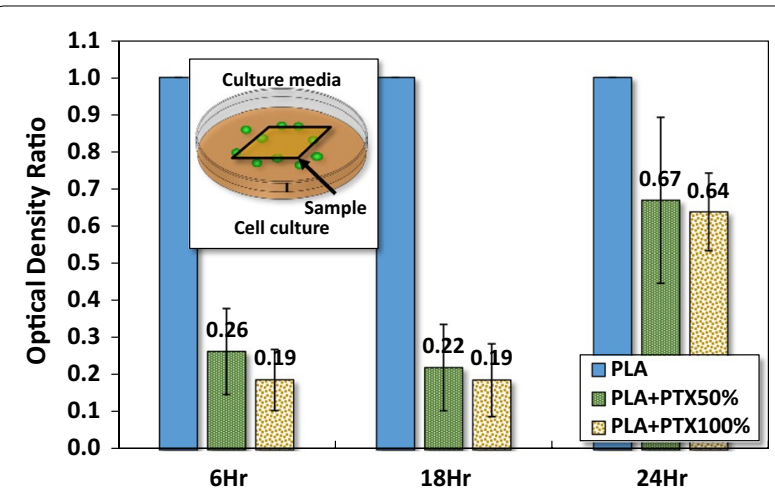

Fig. 8 MTT assay for HCT-116 cultured in media with PLA nanofibers mixed with different concentrations of paclitaxel. The optical density is $\log _{10}\left(\frac{\text { incident light intensity }}{\text { transmitted light intensity }}\right)$ and the optical density ratio is $\frac{O D_{\text {specific group }}}{\mathrm{OD}_{\text {control }}}$

\section{Toxicity of PLA/paclitaxel mixed nanofibers}

Next, PLA or PLA/paclitaxel nanofiber membrane is immersed in liquid medium for the culture of HCT116. Figure 8 presented the optical density ratio from the MTT assay of HCT-116 cells which were cultured in the presence of PLA or PLA/PTX50\% or PLA/PTX100\% nanofiber membrane in liquid medium for $6 \mathrm{~h}, 18 \mathrm{~h}$ and $24 \mathrm{~h}$. The control group included HCT-116 cells cultured in liquid medium in the presence of PLA nanofiber membrane. The optical density ratio of HCT-116 cells at each time point was determined as one for the control as mentioned above because there is an absence of paclitaxel in the liquid medium. After $6 \mathrm{~h}$ of culture, the optical density ratio of HCT-116 cells was reduced by $74 \%$ and $81 \%$ in PLA/PTX50\% or PLA/PTX100\% containing medium, respectively, compared with that for cells in control group (with PLA nanofiber membrane). Similarly, the optical density ratio of HCT-116 cells was reduced by $78 \%$ and $81 \%$ in PLA/PTX50\% or PLA/PTX100\% containing medium, respectively, compared with that for cells in control group after $18 \mathrm{~h}$ of cell culture. The result indicated that the prolonged release of paclitaxel was maintained by the PLA nanofiber carrier within $18 \mathrm{~h}$ of drug adminstration. After $24 \mathrm{~h}$ of cell culture, the optical density ratio of $\mathrm{HCT}-116$ cells was reduced by $33 \%$ and $36 \%$ in PLA/PTX50\% or PLA/PTX100\% containing medium, respectively, compared with that for cells in control group after $24 \mathrm{~h}$ of cell culture.

Figure 9 showed a phase contrast image under 100X magnification of cultured HCT-116 in the presence of PLA or PLA/PTX50\% nanofiber membrane in liquid medium after $24 \mathrm{~h}$ of cell seeding. In the absence of paclitaxel in PLA nanofiber sample, HCT-116 cells populating at high density on the membrane surface displayed more elongated cell shpe corresponding to the normal
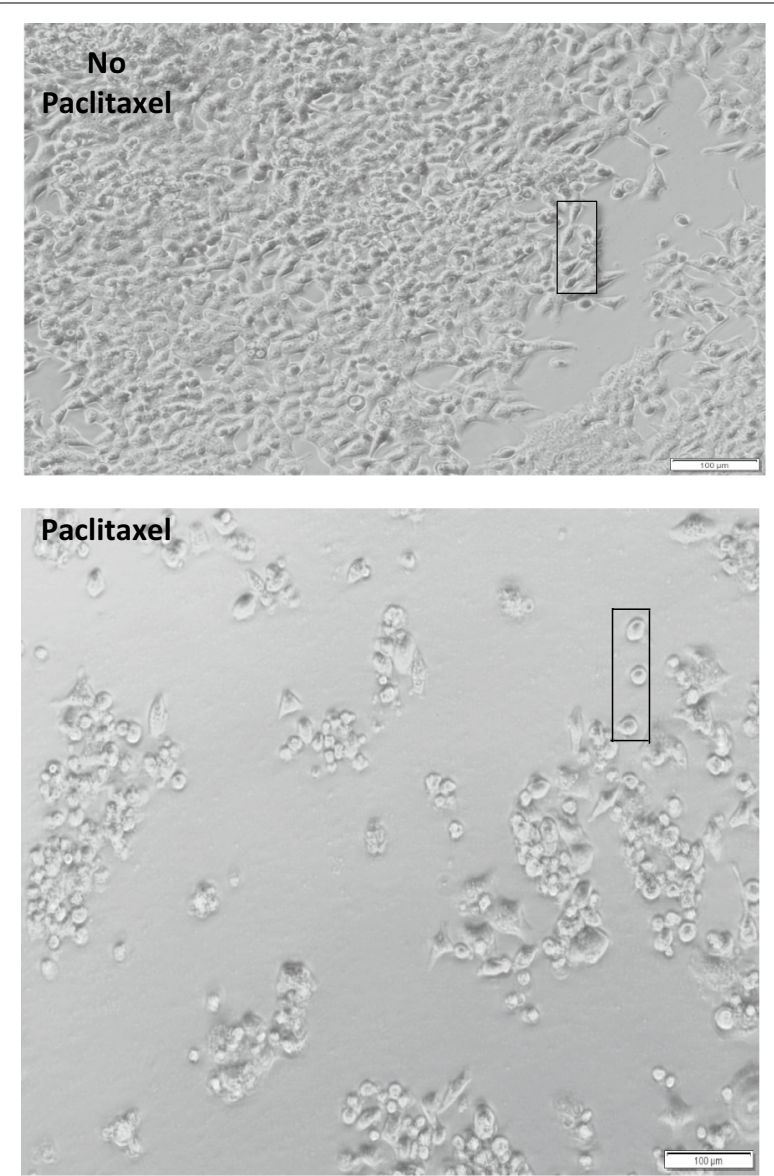

Fig. 9 The 100X optical images of cultured HCT-116 on PLA or PLA/ PTX50\% nanofiber membrane

morphology of this cell line as shown by the formation of membrane extensions. In contrast, most HCT-116 cells rounded up by transforming into a circular shape rather than the usual stretched and randomly stack

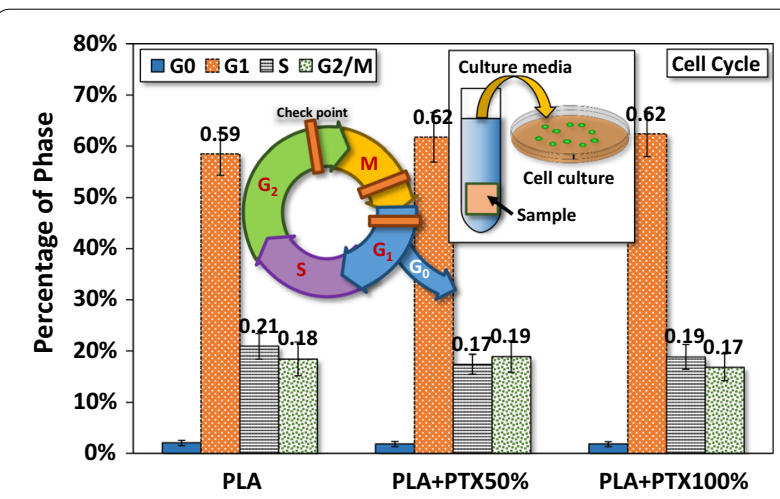

Fig. 10 Percentage of different phases in the cell cycle ( $24 \mathrm{~h}$ after seeding) of HCT-116 cultured in media drawn from immersed PLA/ paclitaxel mixed nanofibers 
up morphology (see the selected view) due to the loss of proliferative activities of the cancerous cells. At the same time, the cell density on the petri dish was significant reduced by PLA/PTX50\% compared to that of PLA. The result indicated that paclitaxel acted as an effective toxic molecules presented to HCT-116 cells in the liquid medium before the cells were able to adhere on the nanofiber modified surfaces.

\section{Cell cycle}

Figure 10 showed the percentage of different phases within the cell cycle of HCT- 116 cells after $24 \mathrm{~h}$ of seeding in the liquid medium pre-incubated with PLA or PLA/PTX50\% or PLA/PTX100\% nanofiber membrane. In spite of the change in the concentrations of paclitaxel in the nanofiber membrane, HCT-116 in the $\mathrm{G}_{1}$ phase $(\sim 60 \%)$ overwhelms all others in other phases of cell cycle. Intuitively, $G_{1}$ phase occurs when cells grow normally through the synthesis of various enzymes and nutrients for getting ready for DNA replication in the $S$ phase. The result indicated that most HCT-116 cells stay in $\mathrm{G} 1$ phase $24 \mathrm{~h}$ after seeding without going into $\mathrm{S}$ phase through the G1 checkpoint. Secondly, around 20\% of cells was at either $S$ or $\mathrm{G}_{2} / \mathrm{M}$ phases cultured with liquid medium which was pre-incubated with either PLA or PLA/PTX50\% or PLA/PTX100\% nanofiber membrane.

Different concentrations of paclitaxel have different impacts on the apoptosis of cancer cells. Under a low concentration $(<200 \mathrm{nM})$, the cell cycle may not be directly affected as paclitaxel may not be able to alter the overall architecture of the microtubules [10,31-34]. The cell can still maneuver into prometaphase and arrested at the G2/M phase then followed by p34, cdc2 activation and Bcl-2 phosphorylation, leading to the eventual apoptosis $[10,33-39]$. In our cases, the released paclitaxel concentration is estimated at around $32-68 \mathrm{nM}$ for the optical density ratio of 0.26 and 0.19 respectively. It could be concluded that the anticancer effect is attributed to the lower concentration of paclitaxel, which would have a direct impact on the microtubules of HCT-116, e.g., increased difficulty in passing thought the $\mathrm{S} 1$ checkpoint but not the overall mitosis [38-42].

\section{Discussion}

The emergence of nanocomposites has led to development of advanced thin-film for drug delivery applications [43]. Moreover, the development of new cancer therapeutics requires complementary molecular carriers with new physiochemical properties [44]. A PLA/PTX nanofiberbased thin film was developed herein for the sustained release of cancer therapeutics. SEM was first applied to probe the structure of PLA based nanofibers. Interestingly, the average diameter of plain PLA nanofibers was larger than that of composite nanofibers including PLA + PTX 50\% and PLA + PTX100\%. The trend as mentioned above is brought about by the lower viscosity and more surface charges of PLA/PTX mixture for electrospinning, leading to overcome the surface tension against the formation of a thinner stretch of plain PLA nanofibers [30]. From the FTIR measurements, PLA+PTX50\% and PLA + PTX100\% were supposed to display absorption peaks of paclitaxel in addition to those of pure PLA but only the main peaks of PLA were detected. Since the mass percentage of PLA in either PLA + PTX $50 \%$ or PLA + PTX100\% nanofibers is significantly larger than that of paclitaxel, the adsorption perks of paclitaxel with significantly lower signal to noise ratio did not manage to show up in the complexed nanofiber. Numerical fitting, on the other hand, provided information about absorption peaks that belongs to paclitaxel (data not shown). This serves as a confirmation for the presence of paclitaxel in PLA nanofibers.

From the results of contact angle measurements, it was shown that the complex morphology of nanofiber surface and the mesh-like structures of deposited layer likely influence the interaction between the water droplet and underlying substrate. For instance, water eventually sinks into the porous matrix of the pure PLA nanofiber mesh through diffusion and adsorption, leading to the alteration in hydrophobicity compared to pure PLA coated film [45]. Also, the slight reduction of PLA nanofiber's contact angle upon PTX incorporation is likely caused by the moderation of the solid-liquid interface induced by the complexation between PTX and PLA, as shown in the formation of a hydrogel through the complexation between PLX and amphipathic peptide in aqueous solution [46]. Thus the measurement of water contact angles is only meaningful at the beginning of the test. Nevertheless, the result still can be used as a reference for the relative hydrophilicity among the three types of substrates used herein. The biocompatibility and targeted toxicity of PLA-based nanofiber system were critical to the therapeutic efficacy of the newly developed biomaterial system. Firstly, the MTT results strongly supported that both PLA thin film and PLA nanofiber membrane did not release any toxic debris through its biodegradation, as shown by the unchanged concentration of formazan, relating to cell activity. Interestingly, PLA thin film without the presence of any PLA nanofiber demonstrated the highest cell proliferative activities among all the substrates used herein. The trend as mentioned above was likely caused by the lower hydrophobicity of pure PLA film, in comparison with PLA nanofiber coated substrate, leading to the optimized adsorption of serum protein for promoting cell adhesion and functions [47]. 
Then MTT assay was used to assess the viability of HCT-116 cells under the influence of PLA/PLX nanofibers. The result strongly supported that both PLA/ PTX100\% and PLA/PTX50\% nanofibers are effective in eradicating cancerous cells. Also, the efficacy of PLA/ PTX100\% in the eradication of cancerous cells is slightly higher than that of PLA/PTX50\% during short term release of paclitaxel. This result implied that the accelerated growth of cancerous cells has led to the elevated depletion of Paclitaxel loading released from the PLA/ PTX nanofiber to culture medium. More specifically, the extended proliferation of HCT-116 led to the offset of antineoplastic effect by paclitaxel. However, paclitaxel released from PLA/PTX nanofiber still retained its ability to eradicate HCT-116 cells even after $24 \mathrm{~h}$ of cell seeding. In general, paclitaxel has been known to target tubulin, stopping cell divisions through the intervention of microtubule disassembly, mitotic spindle formation and chromosome segregation within cancerous cells. Most importantly, the result of phase contrast microscopy validated the successful eradication of HCT-116 cells in the cell culture medium, leading to the reduced cell population adhered on the PLA/PTX nanofiber immobilized surface. Thus the presence paclitaxel of in the culture medium should have an direct impact on the morphology of cells. Similar nanofiber-based system has been developed from alginate for the controlled release of silver ions in antimicrobial applications [48].

The results from cell cycle assay revealed that a significant proportion of the cultured cells are in the stage of DNA replication and mitosis in $G_{2}$ and $M$ phases, respectively, leading to the separation of replicated DNA and division into two cells. Thirdly, the percentage of cells in the $\mathrm{G}_{0}$ phase is smallest $(<2.5 \%)$ among all phases of cell cycle. The $\mathrm{G}_{0}$ phase is a period that cells put themselves into a quiescent state, neither dividing nor preparing to divide. Cells decide to move into this phase usually due to some adversary factors or peculiar biological situations. Summarizing these results, we can infer that HCT-116 cells were effectively restrained from DNA replication and subsequent cell division under the current level of released paclitaxel from PLA/PLX nanofiber membrane. One important question is how the released paclitaxel can threaten the growth of HCT-116 during in vitro culture? To answer this question, we need a quantitative estimation of the concentration of paclitaxel in culture media, which is empirically estimated by measuring the optical density ratio from MTT assay on the culture HCT-116 in media mixed with various pre-selected concentrations of paclitaxel. Using conational regression analysis, a fitting function can be determined numerically with statistical errors. Once the fitting function is determined, we can estimate the optical density ratio at a specific concentration of paclitaxel.

\section{Conclusion}

In this study, we fabricated a specially designed PLA platform for cell culture. The electrospun PLA nanofibers mixed with different concentrations of paclitaxel in the form of membrane were deposited on PLA spincoated thin films of the same compositions. The surface morphology of each type of PLA/PTX nanofiber membrane were first probed with SEM, revealing that the average diameter of rather homogeneous PLA or PLA/ PTX nanofibers were about the same, under a uniform distribution under the current setup of electrospinning. Moreover, FTIR confirmed the encapsulation of paclitaxel in PLA nanofiber with the presence of both molecular vibrational modes of PLA and paclitaxel components. These PLA/PTX nanofiber membrane is also slightly less hydrophobic, based on the high water contact angle in comparison with that of PLA nanofiber membrane. The effect of the encapsulated paclitaxel on the proliferation and cell cycle of cancerous cells was probed with MTT assay and cell cycle assay for HCT-116 cells in liquid culture media pre-incubated with PLA/paclitaxel nanofiber membrane. The results strongly indicated that paclitaxel has a prolonged impact on the cell proliferation up to $24 \mathrm{~h}$ after the seeding. Since the released concentration of paclitaxel is not high $(<100 \mathrm{nM})$, it has a subtle impact on the cell cycle through the enforcement of G1 checkpoint, with majority of cells in G1 phase at $24 \mathrm{~h}$ after the seeding. The results have demonstrated the potential of a new PLA/paclitaxel nanofiber-based system as a sustained release patch for post-surgical drug delivery of cancer therapeutics.

\section{Abbreviations}

PLA: Polylactic acid; PTX: Paclitaxel; FTIR: Fourier-transform infrared spectroscopy; SEM: Scanning electron microscope.

\section{Acknowledgements \\ Not applicable.}

\section{Authors' contributions}

Authors HYC and PHL have performed literature research and experimental work. VC and CL carried experimental design, drafted and revised the manuscript. JHH carried formal analysis, supervision, and project administration and reviewed the manuscript. YHT supervised cell culture experiments and instrumentation operations. YC strategizes the project executions and experimental planning, and reviewed the manuscript. All authors read and approved the final manuscript.

\section{Funding}

Research reported in this publication was supported by Far Eastern Memorial Hospital under contract number 108DN05. VC was supported by the Khalifa University of Science and Technology under Award No. [CIRA-2018-02]. The funding bodies played no role in the design of the study and collection, analysis, and interpretation of data and in writing the manuscript. 


\section{Availability of data and materials}

The data and materials from this study are available from the corresponding authors on reasonable request.

\section{Ethics approval and consent to participate}

Not applicable.

\section{Consent for publication}

Not applicable.

\section{Competing interests}

The authors declare that they have no competing interests.

\section{Author details}

${ }^{1}$ Division of Cardiovascular Surgery, Department of Surgery, Taoyuan Armed Forces General Hospital, Taoyuan 32551, Taiwan. ${ }^{2}$ Department of Biomedical Engineering, Khalifa University, PO Box 127788, Abu Dhabi, United Arab Emirates. ${ }^{3}$ Department of Biomedical Engineering, National Yang Ming University, Taipei 11221, Taiwan. ${ }^{4}$ Department of Materials Engineering, Ming Chi University of Technology, Taishan, New Taipei City 24301, Taiwan. ${ }^{5}$ Department of Surgery, Far Eastern Memorial Hospital, Banqiao, New Taipei City 22060, Taiwan.

Received: 3 August 2020 Accepted: 17 September 2020

Published online: 23 October 2020

\section{References}

1. Kricheldorf HR, Kreiser-Saunders I, Jürgens C, Wolter D (1996) Polylactides - synthesis, characterization and medical application. Macromol Symp 103:85-102

2. Jacobsen S, Fritz HG, Degée Ph, Dubois Ph, Jérôme R (1999) Polylactide (PLA) - a new way of production. Polym Eng Sci 39:1311-1319

3. Mihai M, Huneault MA, Favis BD, Li H (2007) Extrusion foaming of semicrystalline PLA and PLA/thermoplastic starch blends. Macromol Biosci 7:907-920

4. Kramschuster A, Turng LS (2010) An injection molding process for manufacturing highly porous and interconnected biodegradable polymer matrices for use as tissue engineering scaffolds. J Biomed Mater Res B 92B:366-376

5. Alabbasi A, Liyanaarachchi S, Bobby Kannan M (2012) Polylactic acid coating on a biodegradable magnesium alloy: an in vitro degradation study by electrochemical impedance spectroscopy. Thin Solid Films 520:6841-6844

6. Serra T, Planell JA, Navarro M (2013) High-resolution PLA-based composite scaffolds via 3-D printing technology. Acta Biomater 9:5521-5530

7. Socinski MA, Bondarenko I, Karaseva NA, Makhson AM, Vynnychenko I, Okamoto I, Hon JK, Hirsh V, Bhar P, Zhang H, Iglesias JL, Renschler MF (2012) Weekly nab-paclitaxel in combination with carboplatin versus solvent-based paclitaxel plus carboplatin as first-line therapy in patients with advanced non-small-cell lung cancer: final results of a phase III trial. J Clin Oncol 30:2055-2062

8. Gradishar WJ, Tjulandin S, Davidson N, Shaw H, Desai NB, Bhar P, Hawkins M, O'Shaughnessy J (2005) Phase III trial of nanoparticle albumin-bound paclitaxel compared with polyethylated castor oil-based paclitaxel in women with breast cancer. J Clin Oncol 23:7794-7803

9. Kingston DGI (1991) The chemistry of taxol. Pharmacol Ther 52:1-34

10. Wang TH, Wang HS, Soong YK (2000) Paclitaxel-induced cell death: where the cell cycle and apoptosis come together. Cancer-Am Cancer Soc 88:2619-2628

11. Brito DA, Yang Z, Rieder CL, Conly L (2008) Microtubules do not promote mitotic slippage when the spindle assembly checkpoint cannot be satisfied. J Cell Biol 182:623-629

12. Saville MW, Lietzau J, Pluda JM, Wilson WH, Humphrey RW, Feigel E, Steinberg SM, Broder S, Yarchoan R, Odom J, Feuerstein I (1995) Treatment of HIV-associated Kaposis sarcoma with paclitaxel. Lancet 346:26-28

13. Ganguly A, Yang H, Cabral F (2010) Paclitaxel-dependent cell lines reveal a novel drug activity. Mol Cancer Ther 9:2914-2923
14. Chieng BW, Ibrahim NA, Then YY, Loo YY (2014) Epoxidized vegetable oils plasticized poly(lactic acid) biocomposites: mechanical, thermal and morphology properties. Molecules 19:16024-16038

15. Boua-In K, Chaiyut N, Ksapabutr B (2010) Preparation of polylactide by ring-opening polymerisation of lactide. Optoelectron Adv Mat-Rapid Comm 4:1404-1407

16. Hoidy WH, Ahmad MB, Al-Mulla EAJ, Ibrahim NAB (2010) Preparation and characterization of polylactic acid/polycaprolactone clay nanocomposites. J Appl Sci 10:97-106

17. Cui M, Liu L, Guo N, Su R, Ma F (2015) Preparation, cell compatibility and degradability of collagen-modified poly(lactic acid). Molecules 20:595-607

18. Wang DK, Varanasi S, Fredericks PM, Hill DJT, Symons AL, Whittaker AK, Rasoul F (2013) FT-IR characterization and hydrolysis of PLA-PEG-PLA based copolyester hydrogels with short PLA segments and a cytocompatibility study. J Polym Sci A Polym Chem 51:5163-5176

19. Elzein T, Nasser-Eddine M, Delaite C, Bistac S, Dumas P (2004) FTIR study of polycaprolactone chain organization at interfaces. J Colloid Interf Sci 273:381-387

20. Khatiwala VK, Shekhar N, Aggarwal S, Mandal UK, Mandal UK (2008) Biodazsegradation of poly( $\varepsilon$-caprolactone) (PCL) film by Alcaligenes faecalis. J Polym Environ 16:61-67

21. Kemala T, Budianto E, Soegiyono B (2012) Preparation and characterization of microspheres based on blend of poly(lactic acid) and poly( $\varepsilon$-caprolactone) with poly(vinyl alcohol) as emulsifier. Arab J Chem 5:103-108

22. Benkaddour A, Jradi K, Robert S, Daneault C (2013) Grafting of polycaprolactone on oxidized nanocelluloses by click chemistry. Nanomaterials 3:141-157

23. Yu H, Jia Y, Yao C, Lu Y (2014) PCL/PEG core/sheath fibers with controlled drug release rate fabricated on the basis of a novel combined technique. Int J Pharm 469:17-22

24. Liu H, Zhang B, Shi H, Jiao K, Fu X (2009) Biomolecule-assisted hydrothermal synthesis ZnSe nanocrystallites and its application as oligonucleotides label. J Disper Sci Technol 30:495-499

25. Linder R, Seefeld K, Vavra A, Kleinermanns K (2008) Gas phase infrared spectra of nonaromatic concentrations of paclitaxel. Chem Phys Lett 453:1-6

26. Hansrot MZ, "Detection of some aliphatic concentrations of paclitaxel using MALDI-TOF MS and FTIR," M. Sc. thesis, biochemistry with professional experience BSC (Hons), University of Leeds, UK, Aug. 2013. https:// www.researchgate.net/publication/258516824. Accessed 19 Sep 2018

27. Venkatasubbu GD, Ramasamy S, Avadhani G, Ramakrishnan V, Kumar $J$ (2013) Surface modification and paclitaxel drug delivery of folic acid modified polyethylene glycol functionalized hydroxyapatite nanoparticles. Powder Technol 235:437-442

28. Totiger SB, Hiremath JG (2011) Paclitaxel loaded poly (sebacic acid-coricinoleic ester anhydride)-based nanoparticles. Asian J Pharm 5:225-230

29. Devi TSR, Gayathri S (2010) FTIR and FT-Raman spectral analysis of paclitaxel drugs. Int J Pharm Sci Rev Res 2:106-110

30. Chen Y, Lin J, Fei Y, Wang H, Gao W (2010) Preparation and characterization of electrospinning PLA/curcumin composite membranes. Fibers Polym 11:1128-1131

31. Ponnathpur V, Ibrado AM, Reed JC, Ray S, Huang Y, Self S, Bullock G, Nawabi A, Bhalla K (1995) Effects of modulators of protein kinases on taxol-induced apoptosis of human leukemic cells possessing disparate levels of p26BCL-2 protein. Clin Cancer Res 1:1399-1406

32. Wolfson M, Yang CPH, Horwitz SB (1997) Taxol induces tyrosine phosphorylation of Shc and its association with Grb2 in murine RAW 264.7 cells. Int J Cancer 70:248-252

33. Sorger PK, Dobles M, Tournebize R, Hyman AA (1997) Coupling cell division and cell death to microtubule dynamics. Curr Opin Cell Biol 9:807-814

34. Li Y, Benezra R (1996) Identification of a human mitotic checkpoint gene: hsMAD2. Science 274:246-248

35. Li Y, Gorbea C, Mahaffey D, Rechsteiner M, Benezra R (1997) MAD2 associates with the cyclosome/anaphase-promoting complex and inhibits its activity. Proc Natl Acad Sci USA 94:12431-12436

36. Taylor SS, McKeon F (1997) Kinetochore localization of murine Bub1 is required for normal mitotic timing and checkpoint response to spindle damage. Cell 89:727-735 
37. Taylor SS, Ha E, McKeon F (1998) The human homologue of Bub3 is required for kinetochore localization of Bub1 and a Mad3/Bub1-related protein kinase. J Cell Biol 142:1-11

38. Minshull J, Straight A, Rudner AD, Dernburg AF, Belmont A, Murray AW (1996) Protein phosphatase 2A regulates MPF activity and sister chromatid cohesion in budding yeast. Curr Biol 6:1609-1620

39. Minshull J, Sun H, Tonks NK, Murray AW (1994) A MAP kinase-dependent spindle assembly checkpoint in Xenopus egg extracts. Cell 79:475-486

40. Wang TH, Wang HS, Soong YK (2000) Paclitaxel-induced cell death where the cell cycle and apoptosis come together. Cancer 88:2619-2628

41. Ren X, Zhao B, Chang H, Xiao M, Wu Y, Liu Y (2018) Paclitaxel suppresses proliferation and induces apoptosis through regulation of ROS and the AKT/MAPK signaling pathway in canine mammary gland tumor cells. Mol Med 17:8289-8299

42. Huisman C, Ferreira CG, Bröker LE, Rodriguez JA, Smit EF, Postmus PE, Kruyt FAE, Giaccone G (2002) Paclitaxel triggers cell death primarily via caspase-independent routes in the non-small cell lung cancer cell line NCl-H4601. Clin Cancer Res 8:596-606

43. Ates B, Koytepe S, Ulu A, Canbolat G, Thakur VK (2020) Chemistry, structures, and advanced applications of nanocomposites from biorenewable resources. Chem Rev. https://doi.org/10.1021/acs.chemrev.9b00553
44. Sharma PC, Goyal R, Sharma A, Sharma D, Saini N, Rajak H, Sharma S, Thakur VK (2020) Insights on fluoroquinolones in cancer therapy: chemistry and recent developments. Mat Today Chem 17:100296

45. Lertphirun K, Srikulkit K (2019) Properties of poly(lactic acid) filled with hydrophobic cellulose/SiO2 composites. Int J Poly Sci 2019:7835172

46. Liu J, Zhang L, Yang X, Zhao X (2011) Controlled release of paclitaxel from a self-assembling peptide hydrogel formed in situ and antitumor study in vitro. Int J Nanomed 6:2143-2153

47. Qi Y, Ma HL, Du ZH, Yang B, Wu J, Wang R, Zhang XQ (2019) Hydrophilic and antibacterial modification of poly(lactic acid) films by $\psi$-ray irradiation". ACS Omega 4:21439-21445

48. Wróblewska-Krepsztul J, Rydzkowski T, Michalska-Pożoga I, Thakur VK (2019) Biopolymers for biomedical and pharmaceutical applications: recent advances and overview of alginate electrospinning. Nanomaterials 9:404

\section{Publisher's Note}

Springer Nature remains neutral with regard to jurisdictional claims in published maps and institutional affiliations.
Ready to submit your research? Choose BMC and benefit from:

- fast, convenient online submission

- thorough peer review by experienced researchers in your field

- rapid publication on acceptance

- support for research data, including large and complex data types

- gold Open Access which fosters wider collaboration and increased citations

- maximum visibility for your research: over 100M website views per year

At BMC, research is always in progress.

Learn more biomedcentral.com/submissions 